\title{
Collaborative environment for energy-efficient buildings at an early design stage
}

\author{
M. Bassanino \& T. Fernando \\ University of Salford, Salford, UK
}

J. Masior ${ }^{\mathrm{a}}$, M. Kadolsky ${ }^{\mathrm{b}}$, R. J. Scherer ${ }^{\mathrm{b}}$, F. Fouchal ${ }^{\mathrm{c}}$, T. M. Hassan ${ }^{\mathrm{c}}$, S. Firth ${ }^{\mathrm{c}}$, T. Mäkeläinen \& K. Klobut ${ }^{\mathrm{d}}$

${ }^{a}$ Fraunhofer IAO, Stuttgart, Germany,

${ }^{b}$ Institute of Construction Informatics, Technische Universität Dresden, Dresden, Germany,

${ }^{c}$ Loughborough University, Loughborough, UK

${ }^{d}$ VTT Technical Research Centre of Finland, Helsinki, Finland

ABSTRACT: This paper provides an approach for creating a collaborative environment for energy efficient buildings highlighting the issues required to be addressed at an early design phase. The paper will discuss a design scenario for a new built and suggest system architecture for implementing such scenario through the use of advanced simulation tools and modelling techniques to improve current practice in an early design phase. The suggested system architecture will allow multi-disciplinary teams to collectively and individually explore various energy solutions in a 3D interactive workspace to achieve optimum energy efficiency at building level.

\section{INTRODUCTION}

Montiel-Overall defines collaboration as "a trusting, working relationship between two or more participants involved in shared thinking, shared planning and shared creation" (Montiel-Overall 2005). This definition places collaboration at the heart of any construction project because the nature of these projects requires the involvement of a large number of stakeholders with different specializations (Wikforss \& Lofgren 2007), cultures, skills and disciplines ( $\mathrm{Lu} \&$ Sexton 2006). However, irrespective of this diversity, multi-disciplinary project teams need to collaborate in order to produce the final product.

The fact that energy is increasingly becoming an important design factor for producing more energy efficient buildings, and also a policy of both the UK government and the European Commission to reduce carbon emission (Commission 2005), adds to the complexity of collaboration of multi-disciplinary project teams.

Lawson et al (Lawson et al. 2003) argue that construction projects can go right or wrong according to one or more of 3Ps: Process, Product and Performance. In recent years, there has been a shift in architectural theory and practice from 'what the building is about' to 'what the building does'. In other words, the shift has been from 'Product' to 'Performance' (Branko \& Malkawi 2005). Numerous studies such as government reports (Egan, 1998, Latham, 1994) and research work ( Bassanino et al. 2001, Blyth \& Worthington 2001) emphasised that early consideration of performance issues from an early design phase can lead to better outcome and reduce running cost.

In order to consider energy performance within the context of the project life cycle, the Design4Energy project has selected three scenarios to illustrate design activities. The first scenario concerns considering a neighbourhood energy trading context in building design. The second scenario, which is the focus of this paper, is about holistic energy design optimisation during early design phase. The third scenario is about the use of operational and maintenance data in retrofit. These three scenarios will be used as the basis for defining the user requirements and the system architecture definition of the overall Design4Energy technology platform. However, this paper is focused on the collaboration aspect of the Design4Energy platform, taking the second scenario on holistic design optimisation at building level as the context. The key research questions that are planning to be addressed in creating this collaboration platform are:

- RQ1: What type of unified data model could help stakeholders to collaborate and perform both pre-design (strategic) and detailed design exploration?

- RQ2: Can we create a component library that allows stakeholders to explore various design options?

- RQ3: What type of maintenance and operational information are useful for making design decisions?

- RQ4: What are the characteristics of a collaborative platform required to enhance 
collaborative design teams to enable them produce more energy efficient buildings?

This paper presents our initial approach for addressing these research questions.

\section{RELATED WORK}

Previous research in collaborative working environments has explored collaboration challenges in a range of sectors. For example, the CoSpaces project (Fernando et al. 2013) proposed a conceptual system architecture to support collaborative working in which multi-functional teams are provided with tools to enhance communication (Bassanino et al. 2013) and explore various design options. However, this research did not explore collaboration in the context of energy efficiency that involves energy related databases, simulation and collective knowledge exploration involving experts from a wide range of engineering disciplines in real-time.

Collaboration work starts with creating a common understanding of various design data inputs and their inter-relationships. This implies the need for consolidating a range of heterogeneous data sources and creating a unified data model that describes the form, function and performance of the building. Several approaches have been explored in creating a unified data model. For example, Willenbacher (2002) proposes a generic link-based building modelling approach where the entire information is split into partial models and held together by links between them. Other researchers (Fuchs et al. 2010) showed how the linking of different raw data models, called elementary models, can be interlinked with a light-weight XML format at a generic level. In contrast to this, the approaches of the eeBIM (energy enhanced BIM) realisation made in the European projects HESMOS (2010) and ISES (2011) are examples of a more specialized approach. Here, integrated model approaches were developed supporting the energy performance analyses of buildings, based on IFC-BIM.

A few FP7 projects have demonstrated different principles for building component libraries with static and dynamic attributes to provide building component designs. The ISES project developed a design module containing a product catalogue for the selection and testing of new products, which also has interfaces for tools that produce and export IFC model data. It also has a cloud service that deals with the access to external information resources such as climate databases, stochastic templates and user profiles (ISES, 2011). EnPROVE project proposed methodologies for decision making and integrate external resources of building information. The HESMOS project developed a simulation system that integrates different key performance indicators such as operational costs, ventilation or
$\mathrm{CO} 2$ emission in the various stages of the building lifecycle. The interconnection of the system modules is mainly based on the IFC data format and deploys cloud storage technologies. Building on this approach, Design4Energy plans to allow seamless integration of simulations and user interaction that is required in multi-functional team environments for designing energy efficient buildings. Furthermore, a service-oriented, openly accessible library is needed to provide neighbourhood level technologies with a standardized and continuous content updates. This technological information should be presented within the context of multi-simulation environment that can address customer requirements in the building lifecycle. Furthermore, as suggested in the REViSITE roadmap (2012), significant developments have to be done in model based design and information sharing, re-usable design with rich search capabilities and standardisation of data models and performance indicators.

A variety of sensors is used in buildings to produce information on environment and energy performance. Sensors have been designed to produce information on occupancy, and even position measurement (Wolffenbuttel et al. 1990), for detection of chemicals and humidity sensing (Delapierre et al. 1983), and to determine readings for light, radiation, temperature, sound, strain, pressure, position, velocity, and direction (Ermes et al. 2008, Stanford 2004). All these parameters are used to directly or indirectly measure energy. Design4Energy plans to explore how the operational and maintenance data collected through such sensors could be used in creating better design solutions for both new buildings and retrofits.

\section{METHODOLOGY}

A detailed description of the overall Design4Energy methodology can be found in (Mäkeläinen et al. 2014) explaining the use of both top down and bottom up approaches in defining a set of usage scenarios. In our top down approach, we deployed the outcome of several roadmaps which have conducted thorough analysis of current design methodologies, current ICT tools, and possible future scenarios to provide a visionary approach for future design methodologies. For example, ICT road maps such as REEB and REViSITE have identified a direction for building design. The REViSITE road map (2012) recognises the need for holistic design of the interactions between different subsystems; interoperability between CAD tools, applications for design, performance analysis, simulation, visualisation, libraries, etc. This holistic design is advocated in the REEB road map (Hannus et al. 2010) to ensure that buildings meet energy efficiency requirements of regulations and users in the short time, extended to cover the whole life cycle 
for the medium term. Design4Energy have taken these challenges on board and defined its own visions as presented in (Mäkeläinen et al. 2014).

Our bottom up approach is driven by analysing the stakeholders, their role and responsibilities as well as design activities, in the context of designing energy efficient buildings. The stakeholders involved in a typical construction project are illustrated in Table 1. Design team members such as architects, clients, contractors, engineers and energy experts need to collaborate together to produce energy efficient buildings. Huifen et al (2003) distinguished four different modes of team collaboration, these are: face to face (same place, same time), synchronous distributed (different place, same time), asynchronous (same place, different time) and asynchronous distributed (different places, different time). This work is focused on team collaboration in both co-located and distributed manner covering both synchronous and asynchronous modes.

During the design process of the collaborative building design scenario, the architect is responsible for the architectural design; therefore he/she needs to collaborate with other team members to reach a sound architectural design. All engineering disciplines (electrical, mechanical, etc.) need to produce their own design and collaborate with other team members to check if their design has any impact on the building design. As indicated in Table 1 , the role of each stakeholder is to bring their expertise to contribute to the design of energy efficient buildings.

Table 1- Stakeholders and their roles and responsibilities

\begin{tabular}{ll}
\hline Stakeholder & Role \\
\hline Developer (Client) & $\begin{array}{l}\text { Ensure energy efficiency is included } \\
\text { in the project brief for both design } \\
\text { and operation. }\end{array}$ \\
Project Manager & $\begin{array}{l}\text { Ensure project meets the client's } \\
\text { requirements for energy taking } \\
\text { quality, time, and budget into } \\
\text { consideration. }\end{array}$ \\
& $\begin{array}{l}\text { Ensure architectural design is energy } \\
\text { efficient }\end{array}$ \\
Architect & $\begin{array}{l}\text { Ensure HVAC design complies with } \\
\text { energy indicators } \\
\text { Mechanical }\end{array}$ \\
Engineer & $\begin{array}{l}\text { Ensure electrical design is energy } \\
\text { Electrical Engineer }\end{array}$ \\
Energy Efficient & $\begin{array}{l}\text { Advise on energy efficient solutions } \\
\text { Expert }\end{array}$ \\
Building Contractor & $\begin{array}{l}\text { Ensure construction is delivered on } \\
\text { time and it meets energy efficient } \\
\text { requirements as set in the client's } \\
\text { brief. } \\
\text { Validate design performance and user } \\
\text { behaviour }\end{array}$ \\
End-User &
\end{tabular}

\section{VISIONARY SCENARIO}

This section presents the scenario that is specific for collaboration among the stakeholders for creating energy efficient buildings.

The scenario starts with the architect sketching a design of a new energy efficient home using a BIM model. In doing so, the architect takes into consideration a number of parameters such as the local weather profile and lighting to decide the house orientation as well as the use of raw material related to carbon emissions before the conceptual design is completed. The architect then, defines the physical appearance of the building including internal spaces, external openings, use of material and so on. Furthermore, the architect takes into consideration the various options for the energy performance of the project's life cycle and cost of future operation and maintenance and discusses various design options with the client to decide the most suitable one.

The design is then passed on to the mechanical and electrical engineers as a BIM model. Once each engineer proposes his/her own design, the system runs a simulation, enabling team members to compare the simulation analysis result with the expected energy indicators. The 3D collaborative environment provides team members the possibility to explore what-if-scenarios and investigate the impact of various parameters on their design to estimate energy performance through the project life cycle from an early design stage. Using the 3D collaborative environment, team members can simulate the impact of weather, occupants' behaviour, component deterioration, material, running cost and propose future maintenance plan. Furthermore, team members can drag components from the DB library to modify their design. Once the design is optimised, validated and approved by all stakeholders, the solution is agreed.

\subsection{Usage scenario activities and requirements}

This section provides a detailed list of activities for the usage scenario identifying the user requirements as well as functional requirements.

Table 2- Design activities with user and functional requirements

\begin{tabular}{llll}
\hline No & \multicolumn{1}{c}{ Activity } & \multicolumn{1}{c}{$\begin{array}{c}\text { User } \\
\text { requirement }\end{array}$} & \multicolumn{1}{c}{$\begin{array}{c}\text { Functional } \\
\text { requirement }\end{array}$} \\
\hline 1 & Architect & Ability to & Ability to \\
& sketches a design & model 3D & visualise and \\
& for a new & sketch & interact with the \\
& eehouse (energy & & 3D sketch
\end{tabular}

efficient house)

using BIM to

create general

block masses. 
Architect

considers local

weather profile

and natural

lighting to decide

house orientation

(balancing

maximising

natural light and

protection from

direct sun light).

3 Architect also

considers use of

raw material

related to $\mathrm{CO} 2$

emissions then

completes

conceptual

design.

4 Architect defines

physical

appearance of the

building,

elevations,

internal spaces,

material to be

used, external

openings and so

on. Architect

discusses various

options with

client to decide

on most suitable

one.

5 Architect sends

design to

Mechanical, and

Electrical

Engineers as a

BIM model. This

triggers a set of

parallel activities

(6a-6f).

6a Mechanical

Engineer

investigates

design of HVAC

system by first

referring to best

practice of

similar projects.

ME then drags

specific

components from

the D4E DB

library.

Engineer runs
Position and Integrate the 3D

manipulate

model against

3D sketch

against the

local GIS.

surroundings. simulate sun and

its impact on the

building.

$\begin{array}{ll}\begin{array}{l}\text { Ability to } \\ \text { define new }\end{array} & \begin{array}{l}\text { Database } \\ \text { associated with }\end{array} \\ \text { materials and } & \mathrm{CO} 2 \text { emission } \\ \text { assess CO2 } & \text { and cost data for } \\ \text { and cost } & \text { various options. } \\ \text { implications. } & \end{array}$

Ability to

Modelling tool

define high

level design

concept with

the client.

for exploring

spaces, external

openings etc.

Ability to

visualise and

explore various

options.

Edit design and assess cost.

$\begin{array}{ll}\text { Ability to } & \text { Shared BIM } \\ \text { share BIM } & \text { repository } \\ \text { model } & \\ \end{array}$

Explore life

cycle issues

including

costs using

various

design

component

options

Access to best

case studies.

Component

based library

with

performance data

over life cycle.

User interface to

present

performance of

the component in

an easy and

understandable

manner.

Simulate and Production of

visualise

models that can simulation

provided in the

D4E system to

analyse his

HVAC design

impact on cost,

thermal comfort,

operation and

maintenance and

component

deterioration.

$6 c$

Mechanical
Engineer then

compares

analysis result

with building's

energy

indicators.

$6 d$

The Electrical

Engineer

investigates

typical user

behaviour data in

the local area and

decides to

introduce the use

of sensors in

lighting fittings

to minimise

energy and

operational cost

to improve

energy

efficiency.

Simulation is re-

run.

$6 e$

To minimise heat

loss of the new

design, the

architect

investigates

various

insulation

options (using

the components

in the database)

for the walls and

roof and run

simulation.

$6 f$

To optimise light

and thermal

comfort levels,

the energy expert

investigates

energy
simulation
data

be used by

thermal

simulators.

Simulate

Integration

between the

integrated BIM

model and

thermal

simulator.

Simulation of

energy

performance

against

component

deterioration.

Compare Ability to

results with

compare analysis

indicators.

with indicators

Ability to

access user

User behaviour

behaviour

data.

models of

Update BIM

similar

building

users.

Modify

electrical

solutions in

the design.

Simulate and

visualise

energy

simulation

data

Ability to

Update BIM

modify

design,

model using

design

simulate and

visualise

energy

simulation

data

model, run

simulation and

visualise

simulation data.

components

from the library.

Run simulation,

and save

simulation

results.

Ability to

Integrated

visualise

both lighting

visualisation of

thermal and

and thermal

lighting level. 


\begin{tabular}{|c|c|c|c|c|c|}
\hline $\begin{array}{l}\text { alternative } \\
\text { solutions to } \\
\text { improve energy } \\
\text { performance for } \\
\text { the external } \\
\text { openings. } \\
\text { Simulation } \\
\text { results confirm }\end{array}$ & $\begin{array}{l}\text { explore } \\
\text { alternatives }\end{array}$ & 11 & $\begin{array}{l}\text { aesthetic and } \\
\text { energy efficient } \\
\text { requirements. } \\
\text { New design is } \\
\text { validated by all } \\
\text { team members, } \\
\text { approved and } \\
\text { solution agreed. }\end{array}$ & $\begin{array}{l}\text { Validate and } \\
\text { approve BIM } \\
\text { model }\end{array}$ & $\begin{array}{l}\text { ee model signed } \\
\text { off and actions } \\
\text { recorded. }\end{array}$ \\
\hline
\end{tabular}

that solution is

energy efficient.

Each member

uploads his/her

modified version

into the

collaborative

workspace.

These changes

are merged into

the master BIM

model.

Team organises a

design review

meeting to go

through various design options

\begin{tabular}{|c|c|c|}
\hline $\begin{array}{l}\text { Architect does } \\
\text { not approve the } \\
\text { solution to } \\
\text { improve } \\
\text { performance of } \\
\text { external } \\
\text { openings due to } \\
\text { aesthetic issues, } \\
\text { so he/she } \\
\text { investigates } \\
\text { another solution. } \\
\text { Architect } \\
\text { uploads modified } \\
\text { BIM model and } \\
\text { re-run } \\
\text { simulation. } \\
\text { Based on the } \\
\text { simulation data, } \\
\text { team members } \\
\text { discuss the } \\
\text { impact of the } \\
\text { new solution in } \\
\text { the } 3 D \\
\text { collaborative } \\
\text { workspace. Team } \\
\text { members agree } \\
\text { architect's } \\
\text { solution which } \\
\text { satisfies both }\end{array}$ & $\begin{array}{l}\text { Ability to } \\
\text { modify } \\
\text { design, } \\
\text { simulate and } \\
\text { visualise } \\
\text { energy } \\
\text { simulation } \\
\text { data }\end{array}$ & $\begin{array}{l}\text { Ability to change } \\
\text { the BIM model } \\
\text { with different } \\
\text { design } \\
\text { components. } \\
\text { Ability to re-run } \\
\text { the simulation } \\
\text { and visualise the } \\
\text { outputs. }\end{array}$ \\
\hline
\end{tabular}

$\begin{array}{ll}\begin{array}{l}\text { Ability to } \\ \text { modify }\end{array} & \begin{array}{l}\text { Update BIM } \\ \text { model with } \\ \text { design, }\end{array} \\ \text { simulate and } & \begin{array}{l}\text { simulation data } \\ \text { visualise }\end{array} \\ \text { energy } & \\ \text { simulation } & \\ \text { data } & \end{array}$

\section{Ability to}

setup and conduct a design review meeting.

Ability to share

BIM model, conduct realtime visualisation, interaction with the emerging design with distributed members. to change

\section{FUNCTIONAL REQUIREMENTS}

By analysing the scenario in Section 4, the following functional component requirements have been identified as important for creating the collaborative design environment:

- Design Component Database with Meta Data: The overall system should have access to a library of components and energy systems.

- GIS Environment: This module should allow the designers to position the early design concept to consider environmental influences.

- BIM Model for Supporting Various Simulations: This BIM model should support data models for interfacing with a range of simulators (thermal, lighting etc.) for assessing various design options, allowing the team to choose the best energy efficient option without compromising the other design perspectives.

- Maintenance and Operation Data: Access to maintenance and operation data as well as user behaviour data for similar buildings could help designers to optimise the performance of the new building.

- Interfacing with Simulators: the overall architecture should support access to a range of simulation services such as thermal, lighting etc.

- Interactive 3D Sketching: This module should allow the designers to create $3 \mathrm{D}$ design concepts using the component library to explore various design options.

- External Web Service: Access to information such as weather forecast over time, energy cost could allow the designers to simulate possible futures.

- Collaborative Visualisation: This module should allow the design team to visualise the evolving design alternatives, simulation data and communicate their expert opinions to each other.

\section{OVERALL SOFTWARE ARCHITECTURE}

In defining the overall system architecture, few aspects such as modularity, expendability and scalability need to be taken into consideration. As stated in (Oasis, 2009), the service-oriented architecture (SOA) provides distributed use of capabilities controlled and governed by different 
providers. Using the SOA approach, each module can be developed as independent service module and connected together in a distributed web platform through a service orchestrator to provide the collaborative design services required by the design team. Therefore, it has been decided to adopt the SOA approach in developing the collaborative design platform of the Design4Energy project. Establishing a SOA technology platform not only means creating service-oriented solutions, but also providing a governance friendly architecture that allows the long-term evolution of the individual services (Erl 2008). As a result, the Design4Energy platform will develop an open platform that will allow others to integrate their energy related service modules to further enhance energy efficiency of future buildings.

In order to present the overall architecture in a comprehensible form, a three layered architecture is used below. The proposed system architecture is comprised of three layers, these are: database layer, service layer and user interface / application layer (Figure 1).

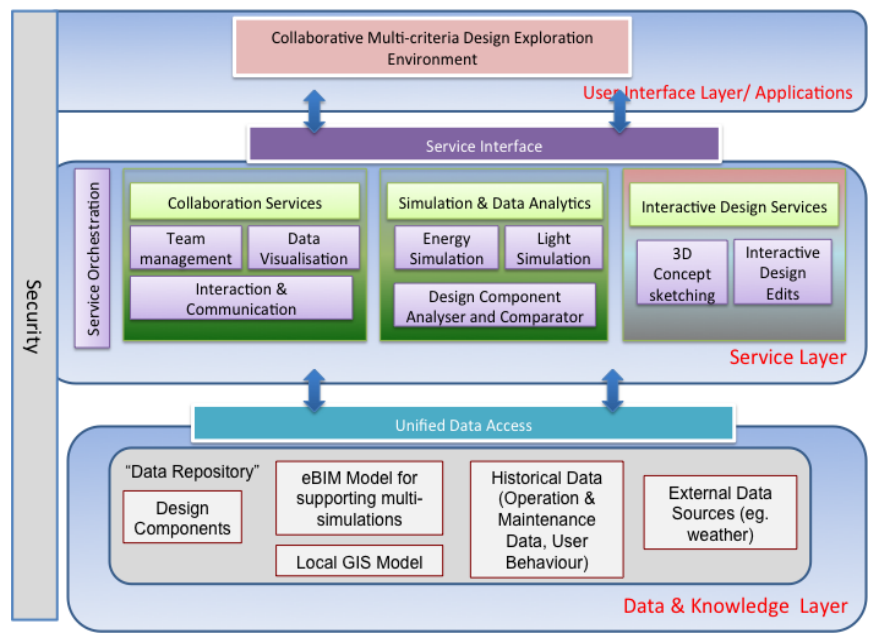

Figure 1. Conceptual design for the system architecture

In this architecture, the data layer will provide access to a range of data sources including design component library, eeBIM model, local GIS data, historical building performance data, long term weather patterns etc. The service layer will provide access to a range of collaboration services, simulation services and interactive design services as indicated in Figure 1. These services can be accessed via a service orchestrator which will support the execution of one or more services according to a pre-defined workflow to provide the desired result. The user interface layer will provide range of user interfaces to visualise the evolving design and its predicted performance.

The following sub sections will discuss each of the energy simulation integration tools, the database of energy components and systems and the maintenance and operation decision tool.

\subsection{EeBIM integration tools}

The envisaged analysis in $\mathrm{D} 4 \mathrm{E}$ that requires a unified data model comprising all data needed for various applications like energy simulation, lighting simulation, etc. as well as operation methods like filtering methods to provide the specific data sets needed for various simulators. For D4E the proposed unified model follows a centralized model approach based on the IFC-BIM model enabling the use of open IFC tools (http://www.openifctools.org). Thereby, for linking the different additional information like weather data, occupancy information, GIS data, etc. with the BIM model the origin IFC-BIM model is modified resulting in an energy enhanced BIM model (eeBIM). To establish the eeBIM model the IFC-schema is reduced to a BIM-schema containing only the IFC-entities required for the applications. However on the other hand the IFC-schema is extended to include IFC concepts for the description of the additional energy relevant information. Thereby, the extension of the BIM model and the linking of the different data are specified by using the extension methods of the IFC like entity types, property sets, etc.

The specification of the eeBIM model goes hand in hand with the development of operation methods bringing the origin data into the specified form as well as operation methods working on the eeBIM model and preparing it to serve as input for the envisaged applications. In both cases the filtering operation represents a key aspect. For D4E it is planned to realise the filtering by using and extending the filter functionality of the JAVA-based filter toolbox BIMfit. BIMfit was developed in the German project Mefisto and further extended in the European projects SARA, HESMOS and ISES. It supports the filtering of building model subsets as well as the filtering of certain elements which fulfill domain or task specific information requirements. The structure of BIMfit is hierarchically organised and comprised of three layers: Neutral Layer, Domain Layer and Application Layer. The Application Layer forms the interface to the end users. It provides necessary functionality for a specific application. Here, a function in this layer invokes and combines functions of the direct layer below. The Domain Layer is managed by software developers. It is based on the Neutral Layer and contains domain specific functions like filter functions for the BIM architecture model domain. The Neutral Layer provides common functions required to identify, select, calculate or extract the data (objects, attribute, relations etc.) from the given mono-model or multi-models. It can be built on (1) a domain specific query language, (2) configurable filter patterns within an external filter service (web service), or (3) an integrated part of a BIM server. 


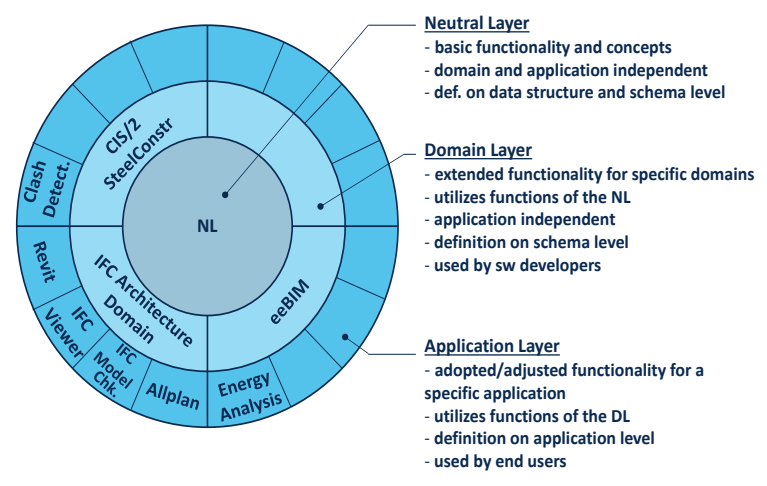

Figure 2. General Approach of BIMfit

\subsection{Database of energy components and systems}

In the concept phase of a building project the choice of building components determines the energy efficiency significantly. On the one side energy related systems such as HVAC systems, building monitoring and management systems, energy use and source systems are chosen. On the other side the designer has to configure building components such as windows, walls, thermal insulation, roofing systems etc. to optimize the energy efficiency. A gap in current practice lies between the collection of customer requirements and the first energy simulations with the configured building components. Energy system solutions that are new for companies are hardly taken into account at the design stage. Designers most commonly make component choices that could potentially have higher costs of operation, maintenance and consumption because of poor knowledge bases. To predict and to influence the performance of energy efficiency, it is necessary to make better informed decisions at building life cycle level, including operation and maintenance. Figure 3 shows a schema of the component or technology related information stored in the database.

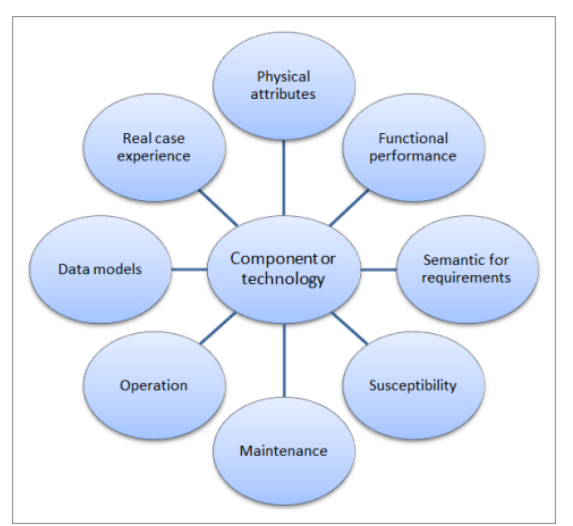

Figure 3- Database schema

The Design4Energy project plans to develop a system that is supported by a database structure that will be used to support the choice of building components by making relevant data available to the stakeholders on a multi-disciplinary platform. The technology based information sharing goes alongside with the common concept of technology management to identify, evaluate and observe technologies, in this case building components (Spath et al. 2010). Contracting parties, solution or service providers have a strong involvement in design decision. They depend on knowledge/information such as budgetary issues, experience of prior projects and performance. In the planned component database the designs or components will be stored to promote re-usability; they can be searched by customer requirements or simple attributes and can easily be taken for further assessments or simulations. Requirements therefore can be applicable in special use cases. Displayed attributes differ depending on the technology type. As an example materials are characterized by type, functionality, thickness, thermal conductivity, density specific heat, internal and external solar absorbance, and emissivity. Furthermore, its characteristics change by age and use case. Additionally, renewable energy generation plants are characterized by performance features depending on climate, weather, age of the plant, operation costs, and historical performance as noted from real cases and susceptibility.

\subsection{Maintenance and operation data}

The sources of information for building maintenance and operation are diverse and hardly coordinated by a variety of stakeholders. These sources can be: (i) sensors and monitoring equipment (including smart home technologies, BMS), (ii) manufacturers specifications, (iii) facility management reports, (iv) case studies, (v) property and condition surveys, repair requests from users or contractors (servicing and work on site); (vi) external: statutory, economic, professional bodies, trade journals, workshops and conferences; (vii) organisational: policies and budgets, past records and archives, services providers, feedback from users, procurement (contact and tender information), staff and personnel; (viii) users: demographics data, ownership status, energy providers data and user behaviour data (Figure 4).

Building maintenance and operation information can be considered: (i) Diverse as they are created by different stakeholders, (ii) Unstructured due to the fact that each maintenance, operation or facility management organisation structures its own information in a different way, (iii) Costly as the value of using maintenance and facility management information is often smaller than the value of creating it, (iv) as time dependent of building maintenance and operation and becomes obsolete overtime, (v) Heterogeneous as the building maintenance information arrive in a variety of forms and formats. This requires the information system to be able to receive, coordinate, store process and present information in a usable format on either 
human information or other digital tools such as BMS or BIM in possible integrated structure.

\begin{tabular}{|l|l|}
\hline \multicolumn{1}{|c|}{$\begin{array}{l}\text { Historical, maintenance and } \\
\text { Operational data }\end{array}$} \\
$\begin{array}{ll}\text { - Data from sensors: } \\
\text { - Temperature }\end{array}$ & $\begin{array}{l}\text { - Facility Management } \\
\text { reports } \\
\text { - Humidity } \\
\text { - Occupancy } \\
\text { - Appliances and other } \\
\text { devices monitoring }\end{array}$ \\
\hline
\end{tabular}

Figure 4- Maintenance and retrofit data

The development of a decision support tool that will provide building design with optimal energy efficiency, a set of data are required. This data could certainly include at least: Metered gas, electricity; Appliance electricity; Rooms temperatures; Outdoor temperature; Radiator temperatures and Occupancy data.

\section{CONCLUSIONS}

This positioning paper presents the initial concepts that are influencing the collaborative environment which is being designed by the Design4Energy consortium. The top down approach adopted in the project has allowed the team to be visionary and the bottom up approach has allowed the team to ensure the buy-in from the stakeholders. The scenario presented in the paper captures the future collaborative design environment based on component based design approach, multi-simulation and team collaboration around a rich eeBIM model. The overall architecture concept, described using the SOA and layered approach provides a foundation for developing a modular and extendable technology platform which could potentially be used by others to integrate their own modules. The paper describes the approach taken for creating the main databases which will be one of the key elements of the overall Design4Energy platform.

\section{ACKNOWLEDGEMENT}

This research is funded by the European Commission under contract FP7-2013-NMP-ENVEeB through the Design4Energy project (Grant agreement no: 609380). We would like to acknowledge all the project's partners in particular the architects for their valuable contribution to this work.

\section{REFERENCES}

Bassanino, M. Fernando, T. \& Wu, K. (2013). Can virtual workspaces enhance team communication and collaboration in design review meetings? Architectural Engineering and Design Management.
Bassanino, M. Lawson, B. Worthington, J. Phiri, M. Blyth, A. \& Haddon, C. (2001). Final Report: Learning from Experience- Applying systematic Feedback to improve the briefing process in construction. Sheffield, : The University of Sheffield.

Blyth, A. \& Worthington, J. (2001). Managing the Brief for Better Design. London, United Kingdom: Spon Press.

Branko, K. \& Malkawi, A. M. (2005). Performative Architecture. NY, USA: Spon Press.

Commission, E. (2005). Doing more with less. Green paper on energy efficiency. Belgium.

Delapierre, G. Grange, H. Chambaz, B. \& Destannes, L. (1983). Polymer-based capacitive humidity senso. Sensors and Actuators, 4(1), 97-104.

Egan, J. (1998). Rethinking Construction: The report of the Construction Task Force to the Deputy Prime Minister, John Prescott, on the scope for improving the quality and efficiency of UK constructio. London, UK: DETR.

Erl, T. (2008). Introducing SOA Design Patterns. SOA World Magazine, 8.

Ermes, M. Parkka, J. Mantyjarvi, J. \& Korhonen, I. (2008). Detection of daily activities and sports with wearable sensors in controlled and uncontrolled contitions. IEEE Transactions on Information Technology in Biomedicine, 12(1), 20-26.

Fernando, T. Wu, K. \& Bassanino, M. (2013). Designing a Novel Virtual Collaborative Environment to Support Collaboration in Design Review Meetings. ITCon, 18, 372-396.

Fuchs, S. Katranuschkov, P. \& Scherer, R. J. (2010). A framework for multi-model collaboration and visualisation. Paper presented at the Proceedings of the European Conference on Product and Process Modeling (ECPPM).

Hannus, M. Kazi, A. S. \& Zarli, A. (2010). ICT Supported Energy Efficiency in Construction; Strategic Research Roadmap and Implementation Recommendations.

HESMOS (2010). EU-Project FP7-ICT (http://hesmos.eu/), Ref 260088.

Huifen, W. Y. Z. Jian, C. Lee, S.F. \& Kwong, W.C. (2003). Feature-based collaborative design. Journal of Materials Processing Technology, 139(1-3), 613-618.

ISES (2011). EU-Project FP7-ICT (http://ises.eu-project.info/), Ref 288819.

Latham, M. (1994). Constructing the Team: Final Report of the government/ industry review of procurement and contractual arrangements in the UK Construction Industry. London, UK.

Lawson, B. Bassanino, M. Phiri, M. \& Worthington, J. (2003). Intentions, practices and aspirations: understanding learning in design. Design Studies, 24(2), 327-329.

Lu, S. L. \& Sexton, M. (2006). Innovation in Small Construction Knowledge-Intensive Professional Service Firms: A case Study of an Architectural Practice. Construction Management and Economics, 24(12), 1269-1282.

Mäkeläinen, T. Klobut, K. Fernando, T. Hannus, M. Sepponen, M. Masior, J. Fouchal, F. Hassan, T. Firth, S. \& Bassanino, M. (2014). New methodology for designing energy efficient buildings in neighbourhoods. Paper presented at the Proceedings of the European COnference on Product and Process 
Modelling (ECPPM), Vienna University of

Technology, Austria.

Montiel-Overall, P. (2005). Toward a theory of collaboration for teachers and librarians. http://www.ala.org/aasl/aaslpubsandjournals/slmrb/sl mrcontents/volume82005/theory

Oasis. (2009). Reference Architecture Foundation for Service Oriented Architecture. Retrieved 10/04/2014, from http://docs.oasis-open.org/soa-rm/soa-ra/v1.0/soa-racd-02.html

REViSITE EU project: Multi-disciplinary Strategic Research Agenda for ICT-enabled Energy Efficiency. (2012). Retrieved 10/04/2014, from http://www.revisite.eu/docs/REViSITE_Book.pdf

Spath, D. Schimpf, S. \& Lang-Koetz, C. (2010). Technologiemonitoring: Technologien identifizieren, beobachten, bewerten. Stuttgart, Germany: Fraunhofer, Verlag.

Stanford, V. (2004). Biosignals offer potential for direct interfaces and health monitoring. IEEE Pervasive Computing, 3(1), 99-103.

Wikforss, O. \& Lofgren, A. (2007). Rethinking Communication in Construction. ITCon, 12, 337-345.

Willenbacher, H. (2002). Interactive link-based building modelling as integration platform for building life cycle. Germany: Weimar: Bauhaus-Universität Weimar.

Wolffenbuttel, R. F. Mahmoud, K. M. \& Regtien, P. L. (1990). Compliant capacitive wrist sensor for use in industrial robot. IEEE Transactions on Instrumentation and Measurements, 39(6), 991-997. 